\title{
TOPOLOGÍAS DE PATERNIDAD, PATRIA Y GUERRA EN LA PRIMERA POESÍA DEL EXILIO DE JOSÉ MARTÍ
}

\author{
Mónica González García \\ Pontificia Universidad Católica de Valparaíso, Valparaíso, Chile \\ monica.gonzalez@pucv.cl
}

\section{RESUMEN/ ABSTRACT}

Considerando el papel de la espacialidad en la configuración de las subjetividades coloniales según el concepto 'topologías del ser' en la elaboración del filósofo puertorriqueño Nelson Maldonado-Torres, analizo el lugar que paternidad, patria y guerra ocupan en la geografía subjetiva imaginada por el yo lírico en Ismaelillo (1882), primera poesía del exilio de José Martí. Siguiendo al crítico cubano Cintio Vitier en torno al valor de ciertos tropos en la poética martiana, propongo también que su primera poesía en el exilio da cuenta incipiente de un clima de época hostil que el yo lírico busca ordenar éticamente bifurcando una metáfora para producir valores opuestos. Esta operación, que llamo tropo antitético, anticipa divisiones ético-poéticas posteriores inspiradas en lo que el crítico puertorriqueño Julio Ramos llama "concepto aurático de cultura" y, según propongo, en el tipo de angustia moderna que en 1919 Sigmund Freud definiría como "lo ominoso".

Palabras Clave: Ismaelillo, José Martí, poesía del exilio, sujeto colonial, topologías del ser.

\section{TOPOLOGIES OF FATHERHOOD, FATHERLAND AND WAR IN JOSÉ MARTI'S EARLY POETRY OF EXILE}

Taking into account the concept of "topologies of Being" with which Puerto Rican philosopher Nelson Maldonado-Torres reflects upon the role of spatiality in the articulation of colonial subjects, I analyze the place that ideas such as fatherhood, fatherland and war occupy in José Marti's poetic configuration of his lyric subjectivity in the early poetry of exile of Ismaelillo (1882). Additionally, I follow the analysis of Cuban critic Cintio Vitier on the value of some tropes in Marti's poetry, in order to propose that the hostile historic atmosphere which the lyric "I" seeks to ethically control through the bifurcation of a single metaphor into opposite ethical meanings. This procedure, which I call antithetical trope, anticipates later ethic and poetic divisions inspired by what critic Julio Ramos defines as an "auratic concept of culture" and, as I suggest, by the type of modern anguish Sigmund Freud would describe in 1919 as "the uncanny". 
KEYWORDS: Ismaelillo, José Martí, poetry of exile, colonial subject, topologies of Being.

Dos años después de su primer contacto con Nueva York el 3 de enero de 1880, José Martí escribía en su prólogo a Ismaelillo: "Hijo: Espantado de todo, me refugio en ti” (41). El volumen de quince poemas dedicado a José Francisco, único descendiente de su crítico matrimonio con Carmen Zayas-Bazán, constituyó la primera creación lírica del cubano tras su exilio definitivo de la isla como consecuencia de su participación en la Guerra Chiquita, extendida entre 1879 y 1880 . Una década antes, el soneto “ 10 de octubre!” y el drama en verso "Abdala", publicados en los albores de la Guerra de los Diez Años, le habían valido la expulsión a la metrópolis. A tono con el romanticismo inspirado por su maestro, el poeta independentista Rafael María de Mendive, la voz épica de este soneto juvenil revela -en fragmentos como "Ruge el cañón, y al bélico estampido,/ El bárbaro opresor, estremecido,/ Gime, solloza, y tímido se aterra" (20) y "Rompe Cuba el dogal que la oprimía/ Y altiva y libre yergue su cabeza!"- que el espacio de la poesía es articulado a partir de un principio de mímesis social que desde el apostrófico título indica que busca universalizar, como el nacimiento de un pueblo, el evento histórico implícito: el "grito de guerra" contra España lanzado en Yara el 10 de octubre de 1868 bajo el liderazgo de Carlos Manuel de Céspedes. Pero si en la adolescencia Martí recoge la poesía del entorno a fin de representar el instante fundacional de la emancipación colectiva, en la adultez ella fluye de su interior, lugar adonde el poeta se retira a procurar el calor de los recuerdos y mitigar los dolores del espíritu. En la ajena geografía del exilio, la poesía se convierte en el refugio que propicia un catártico recorrido por las topografías de lo íntimo: familia, amores, amigos, exilios, sujetas todas ellas al evocado y fraguado territorio de la patria. Así, el desplazamiento geográfico del sujeto poético, primero a Venezuela y luego a Estados Unidos, impulsa la migración del lugar epistémico de su poesía desde la colectividad a la subjetividad: la patria, que localizada al exterior del individuo es objeto de canto en " $i 10$ de octubre!", se traslada al interior de un Martí que en el extranjero la cargará en el alma y la expresará como dialéctica de temporalidades entre las memorias de la tierra natal y las proyecciones para su libertad. De allí que Ismaelillo sea un regreso lírico al origen geográfico alegorizado en la ofrenda de versos al hijo lejano, quien es, a la vez, fracturada sinécdoque de dos ausencias: la Cuba histórica, oprimida, y la imaginada, Cuba libre. 
José Martí distingue este volumen como un deslinde en su creación poética pues le solicita expresamente a su albacea, Gonzalo de Quesada, que no publique versos suyos sino a partir de Ismaelillo, razón por la cual en este estudio lo abordamos como su primera poesía del exilio. El juicio es compartido por la crítica martiana, la que identifica su publicación de 1882 como un momento de inflexión en la sensibilidad poética del idioma: "[c]on los quince poemas de este librito -afirma Cintio Vitier (1978) - comienza la poesía moderna en lengua española” (141). Y Julio Ramos (1989): “es válido pensar al Ismaelillo... como uno de los núcleos generadores de la modernización literaria $[. .$.$] porque su enunciación poética$ se produce desde un campo discursivo ya diferenciado de los discursos disciplinados de la racionalización" (80). Ya en 1958, Iván Schulman había propuesto que la nueva sensibilidad poética venía asomando en la escritura martiana desde su regreso del destierro en España, a mediados de la década de 1870, debido a su contacto con los clásicos del Siglo de Oro y las nuevas formas estilísticas francesas - todo lo cual "Martí plasmó... en un conjunto armónico, cromático, musical, profundamente suyo", y estando "siempre consciente del cambio que estaba operando en la expresión literaria” (63)1. En el presente trabajo leemos Ismaelillo a partir del lugar que la paternidad y la guerra ocupan en las primeras articulaciones de la patria libre que José Martí esboza desde el exilio, dando cuenta, al mismo tiempo, de los síntomas de rechazo a un clima de época que más tarde se manifestará como tensa crítica a la modernidad estadounidense. En este sentido, considerando que la poesía martiana en el exilio es un espacio de refugio, nos preguntamos en qué sentido el temor que le provocan los ruines tiempos nuevos se vincula con el cambio de sensibilidad poética atribuido a este poemario.

Asimismo, leemos estas primeras articulaciones de la patria libre como topologías subjetivas siguiendo la pregunta de Nelson MaldonadoTorres (2004) en torno a "the colonial aspect of Being" y la relación de la espacialidad con la configuración del ser colonial; en el caso de José Martí, la relación de su espacialidad colonial con la creación de geografías poéticas subjetivas en tanto que exiliado por el régimen español. Maldonado-Torres

Ya Rubén Darío había compartido una apreciación similar en 1888 respecto de la prosa martiana, describiéndola como "prosa profusa, llena de vitalidad y de color, de plasticidad y de música, en que se transparenta el cultivo de los clásicos españoles y el conocimiento de todas las literaturas antiguas y modernas" (Cit. en Rojas 22). 
señala que "[t]he introduction of spatiality [can be] a significant factor in the understanding of philosophy and in the production of social theory", porque contribuye a superar la idea de un observador distante "who can only examine the intricate relations between knowledge and ideas of space because she or he is ultimately beyond such relations" (30). Prestando atención a la espacialidad colonial de los sujetos en la configuración de sus saberes, Maldonado-Torres espera poner de manifiesto su potencial para operar como "a critique of roots that brings into light both coloniality and the epistemic potential of non-European epistemes". Siguiendo estas premisas, creemos que las formas poéticas que adquiere la espacialidad del exilio de José Martí resultan cruciales para entender las relaciones que en Ismaelillo se establecen entre paternidad, patria y guerra, así como para distinguir los lugares epistémicos desde donde articula y hacia donde proyecta estas tres coordenadas sustentadoras del yo lírico en su primer poemario del exilio.

$* * *$

La constante de la patria, que en el extranjero aparece poéticamente sintomatizada entre los accidentes geográficos de la subjetividad, se vislumbra inicialmente, en Ismaelillo, detrás de la referencia bíblica contenida en el nombre lírico de "Pepito" y se revela como proyección del porvenir de Cuba. En el "Génesis", libro que exhibe la narrativa fundacional de los israelitas, Ismael es descrito como primer hijo de Abraham y como procreador de los pueblos árabes. La analogía martiana de los primogénitos, sintetizada en el título de la obra, apunta a la esperanza histórica que Martí guarda en relación a su hijo y que podemos deducir del destino que Dios anuncia para Ismael: "le daré una descendencia muy grande y muy numerosa; será padre de doce príncipes y haré de él un gran pueblo" (Gén. 17: 20). Es interesante que el nombre poético escogido sea el del hijo natural de Abraham y no el del hijo legítimo, Isaac, lo cual puede aludir a un cariño de padre obstaculizado por la distancia de los progenitores, pues la madre de Ismael es Agar, la esclava, y no Sara, la esposa. Vitier piensa que la analogía entre Ismael y Pepito se completa con la insinuación simbólica del conflicto conyugal entre José Martí y Carmen Zayas-Bazán, pues el crítico cubano nos recuerda que en el poema XLII de Versos sencillos, publicados en 1891, "año de la ruptura definitiva de su mujer", llama a esta Agar, "es decir, en hebreo, "la fugitiva"... y sobre todo, "la sierva"” ("Trasluces..." 143). Pero la lectura simbólica que nos interesa explorar es la vinculada a la fraternidad homosocial que el poeta asigna al 
apodo filial en tanto síntoma de la patria imaginada: Martí, pese a no tener a Pepito consigo, lo sueña como heredero del pueblo libre que él intenta fundar por medio de la guerra, y por ello utiliza los títulos políticos de "príncipe", "monarca" y "rey". De este modo, el sometimiento del padre al hijo en el texto de Ismaelillo y el contexto de la Cuba colonial -"Monarca de mi pecho,/ Montado alegremente/ Sobre el sumiso cuello,-" ("Sueño despierto" 8); "Úngeme siervo/ Siervo sumiso [...] ¡Lealtad te juro,/ Mi reyecillo!/ Sea mi espalda/ Pavés de mi hijo" ("Mi reyecillo" 22)-, es una anticipación, en el territorio íntimo creado por imágenes domésticas articuladas en lenguaje de cuentos infantiles, del orden que con su propio sacrificio Martí anhela establecer en el espacio público de la futura nación: José Francisco como jefe de Estado de la patria emancipada "[p]orque es necesario que ese hijo mío... no sufra lo que yo he sufrido" (143) y porque "[g]ozo en verle famoso, $\mathrm{y}$ en que le hagan versos, y en que luzca como caballero de importancia, y príncipe de veras, en diarios y revistas" (144).

El universo poético desde donde se proyecta el papel soberano del hijo sugiere que ese será directa consecuencia de la tarea heroica del padre, tarea que se deja entrever en la identidad implícita del yo lírico: si el primogénito versificado es analogía de Ismael, se deduce que la voz poética es analogía de Abraham y su misión original de activar el reloj universal del tiempo humano con la fecundación del pueblo elegido: "No te llamarás más Abram, sino Abraham: porque te tengo destinado a ser padre de muchas naciones. Yo te haré crecer hasta lo sumo; pueblos y reyes saldrán de ti, de generación en generación, para siempre en adelante" (Gén. 17: 5-7). La trascendencia colectiva del nombre con que es rebautizado el personaje bíblico es asimilada por Martí, quien también rebautiza simbólicamente al hijo para conferirle la carga excelsa de un destino histórico. Pero el patriótico vínculo de fraternidad homosocial que el poeta establece con su descendiente se desprende también de una noción patriarcal del lazo biológico: como en la alianza entre Dios y Abraham, la fundación de un pueblo se da por la línea de los varones, de manera que si José Francisco es simbolizado en el título como simiente de Cuba libre, es porque representa tanto el producto biológico como la perpetuación política de la función seminal del padre. Dentro del paradigma fundacional bíblico, poéticamente continuado por Martí y según el cual los pueblos y los reyes salen del cuerpo del hombre elegido, inferimos que la fuente de autoridad política está, en consecuencia, contenida en su capacidad para sembrar las semillas de una nueva sociedad -modelo masculino de civilidad reforzado, en el caso de Abraham, por el rito fálico-religioso que sella su alianza con 
Dios y que avala la mantención de la comunidad. Esto se complementa con lo que dice Sylvia Molloy (1999) respecto a la lectura que Martí hace de Walt Whitman, donde el cubano reconoce en la poesía del estadounidense un modelo de "revolutionary family of sons and fathers confounded in a continuum of natural masculine emotion" (272). Desde esta perspectiva, la patria es un asunto de padres pues son los únicos que pueden engendrarla y continuarla, lógica desde la cual se entiende que el hijo versificado, la voz lírica paterna y la Cuba implícita conformen una nación imaginada desde esa geografía viril que subyace a la poética amorosa de Ismaelillo.

Esta estrecha trinidad, integrada por el padre, el hijo y la patria imaginada que vislumbramos en el poema de entrada, "Príncipe enano", es articulada en un tiempo onírico donde se reúnen la memoria del pueblo oprimido, la inquietud bélica del yo lírico y el destino soberano del hijo ausente -pasado, presente y futuro. El lugar poético imaginado por el amor paterno debe, entonces, transgredir tiempo y espacio a fin de posibilitar el reencuentro con el primogénito -"Hijo, en tu busca/ Cruzo los mares..." (“Amor errante" 25)y permitir la continuación de la labor educadora mediante la edificación de su identidad política. En lenguaje literario, esta trinidad masculina se filtra en la obra como presencia sintomática de una guerra que, entre mimos, rige tácitamente diversas actividades y diálogos que la voz poética establece con su heredero -comunicaciones fantásticas que en última instancia encierran la esperanza de trasladar ese orden subjetivo al tiempo histórico del espacio colectivo mediante el temprano entrenamiento del niño en lúdicas guerras: "¡Heme ya, puesto en armas,/ en la pelea!”, "Mi banda de batalla/ roja y violeta" ("Príncipe enano" 6, 7). La intención paterna de lucha es, en la hermenéutica que se desprende de Ismaelillo, el único recurso capaz de remendar esa rasgada sinécdoque del hijo como recuerdo y como anhelo de patria; y de establecer, a estímulo de amor homosocial, el necesario desplazamiento de la Cuba oprimida a la Cuba libre. En el siguiente fragmento de "Príncipe enano", el intercambio imaginario surge a partir de la proyección sobre el primogénito de la preocupación parental en torno a la guerra; la ambigüedad espaciotemporal del verbo "volver", conjugado en el cuarto verso, no deja claro si, en la semántica del poema, el deseo filial implica un deseo espacial e histórico: que el padre regrese a Cuba a luchar; o uno temporal e íntimo: que el padre luche con él una vez más:

¡Heme ya, puesto en armas, En la pelea! 
Quiere el príncipe enano

Que a luchar vuelva:

¡Él para mí es corona,

Almohada, espuela! (6)

Para Rafael Rojas, la fiesta que escenifica el universo poético en este poema "podría ser leída como una ceremonia política en la que el poeta-súbdito reconstituye simbólicamente su deslealtad hacia el rey de España, Alfonso XII, en lealtad reverencial a un nuevo príncipe, su pequeño hijo José Francisco" (25). Quizás esta sea una clave desde donde se puede explicar que, en la división política de la trinidad masculina martiana integrada por padre, hijo y patria imaginada, el hijo ocupe roles ejecutivos. Ello, además, en el entendido de que el trabajo ingrato de luchar para crear un orden social y gubernamental justo le cabe al padre. Así, la voz poética va construyendo la identidad soñada para el hijo mediante el acrecentamiento del campo semántico de nobles actividades masculinas a las que apela para interpretar sus juegos espontáneos. Es el caso de "Mi caballero", poema en el cual la voz poética visualiza al niño como un pequeño jinete montado en el pecho paterno durante el recreo matinal:

Por las mañanas
Mi pequeñuelo
Me despertaba
Con un gran beso.
Puesto a horcajadas
Sobre mi pecho,
Bridas forjaba
Con mis cabellos.
Ebrio él de gozo,
De gozo yo ebrio,
Me espoleaba
Mi caballero:
¡Qué suave espuela
Sus dos pies frescos!
¡Cómo reía
Mi jinetuelo! [...] (11)

En términos de metro y rima, el poema "Mi caballero" es un romancillo compuesto por cinco estrofas de cuatro versos pentasílabos de rima asonante abab, patrón que el poeta innova, rompiendo la secuencia con la incorporación 
de rimas blancas - como en la tercera estrofa: 5 - 5 - 5a - 5b. "Príncipe enano", por su parte, está estructurado como seguidilla arromanzada, estrofa ibérica de origen medieval compuesta por dos heptasílabos libres y dos pentasílabos asonantes alternados $(7-5 a-7-5 a)$, pero que Martí modifica con variaciones en el número de versos. El ritmo creado por la versificación de arte menor, que evoca bailes populares y canciones infantiles, sugiere que la ofrenda paterna al hijo ausente puede ser leída como un conjunto de melodías que con el fluir de la vocalización amorosa espera hacer llegar al destinatario: "Estos riachuelos han pasado por mi corazón. ¡Lleguen al tuyo!” (41). La estrofa pareada que abre el poema y que clausura los dos grandes segmentos que lo componen, refuerza la comparecencia de ese ingrediente musical propio de celebraciones infantiles: "Para un príncipe enano/ Se hace esta fiesta". El juguetón diminutivo illo con que Martí modifica el apodo "Ismael" puede ser una referencia a estas estrofas, seguidilla y romancillo, gesto que, puesto al lado de la carga bíblica del nombre, habla del lugar epistémico desde donde el padre compone al menos catorce de los quince poemas de Ismaelillo: su deseo privado de perpetuar ese lúdico intercambio de cantos y juegos, proceso en el cual, no obstante, sintomatiza su preocupación pública de carácter bélico por una patria liberada, espacios que se encuentran en la aspiración martiana de incorporar al hijo en la Cuba imaginada.

Aquí cabe señalar lo que indica Rojas en torno a que "la construcción martiana de un repertorio de parentescos espirituales funcionó siempre como una tendencia liberadora frente al dilema de la afectividad privada y la pública, frente a la tensión entre la Familia y la República” (24). Ello en el entendido de que el deber público estaba por sobre el privado, según confiesa Martí durante la escritura de Ismaelillo: "porque amo a mi deber, más que a mi hijo" (Cit. en Rojas 24). No obstante este predominio de lo púbico por sobre lo privado, la edificación lírica del hijo futuro funciona, para el poeta, no solo como fuente de inspiración sino como motivo crucial para continuar la batalla presente por la construcción de la patria: “¿Mi musa? Es un diablillo/ con alas de ángel”., “¡Hijo soy de mi hijo!/ ¡Él me rehace!" ("Musa traviesa” 12, 17); “¿Déjeme que la vida,/ A él, a él ofrezca!” ("Príncipe enano" 7). Ambos, hijo y patria, son proyectos concomitantes de cimentación que resemantizan la identidad individual y colectiva del padre. En este sentido, el poema que acaso revela con mayor intensidad la tensión entre el deber público y el privado, atravesado siempre por la paternidad en el universo (po)ético de Ismaelillo, es “Tábanos fieros”, cuya lucha sin cuartel nos habla del sistema simbólico de significados que comienza a regular la 
tensa relación que Martí establecerá con su tiempo histórico y, más tarde, con los espacios de la modernidad en Estados Unidos. Es a través de esta pieza que podemos emprender una exégesis de aquel alarmado comentario con que abrimos el análisis de Ismaelillo y que el poeta anuncia en su prólogo: "Hijo: Espantado de todo, me refugio en ti". En el poema, escrito como seguidilla, los insectos asustan al padre, no al hijo, e inauguran un glosario de objetos que aluden a todos los "espantos fieros" de los cuales el poeta se resguarda tras un hijo metaforizado como "escudo fuerte" (34). El violento inicio está marcado por la apocalíptica invocación a los animales feroces que vienen perturbando, desde un pasado implícito, a un yo lírico que en el primer verso explota con la impetuosidad de una declaración de guerra:

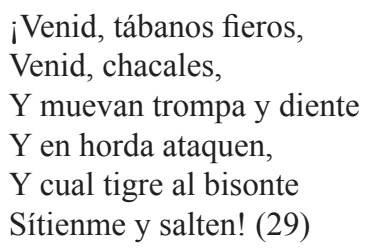

Este es el único poema de la colección que escapa del resguardado territorio onírico de la masculina patria íntima "padre-hijo", para tomar lugar en una zona pesadillesca, ajena y hostil, habitada por toda clase de males en acecho constante. Los tábanos y los chacales son los animales metafóricos que amenazan al yo lírico, quien remetaforiza esta contienda en un símil: "cual tigre al bisonte". Es interesante que la voz poética se corporice como bisonte para entrar a la gramática fáunica con que se inscribe el belicoso argumento del poema, identificación que alude a una entidad noble y migratoria, cuya fuerza la capacita para enfrentar tormentas pero que, sin embargo, no está regida por instintos depredadores ni asesinos. Este cuerpo, por otro lado, puede sugerir el "hábitat" de ese yo lírico, pues se trata de un animal que, además de Europa del Este, habita solo en América del Norte. En este sentido, creemos que la geografía hostil de este poema, habitada por una fauna monstruosa, en cierto modo anticipa su propio migrar por las hostiles geografías de modernidad que conoce en Nueva York. A continuación de la exclamación introductoria, la voz nos comienza a revelar, a través de otro conjunto de imágenes, la identidad social de tábanos y chacales: verde envidia, bella carne, celos voraces, moneda de oro, "tentaciones sordas" (33) a las que el poeta responde con un bramido ético: “¡De virtud mercaderes,/ Mercadeadme!” El uso del adjetivo "sordas" para caracterizar los vicios enumerados refuerza su 
naturaleza perniciosa y disimulada, y la intensidad invisible de su presencia en ese infernal espacio poético, características complementadas con la mención de sus herramientas de seducción:

Cada cual con sus armas

Surja y batalle:

El placer, con su copa;

Con sus amables

Manos, en mirra untadas,

La virgen ágil;

Con su espada de plata,

El diablo bátame:- (30)

Nuevamente la respuesta emerge sólida: “¡La espada cegadora/ no ha de cegarme!"

El resto del poema está dividido en tres secciones: el desarrollo de la batalla inevitable, la reflexión ante la victoria donde aparece un "él" apenas invocado, y la retirada final al refugio en compañía de un hijo "volante". Cabe señalar en este punto las características del hijo como musa que distingue Cintio Vitier en "Trasluces de Ismaelillo": “...la novedad de su musa es siempre de raíz solar, como podría comprobarse con el censo de signos luminosos, de encendimiento, pureza, crisopopeya, fuerza y realeza, que en estas páginas se oponen triunfantes a los signos negativos de antro, impureza, envejecimiento y palidez" (147). La pureza del signo solar identificado por los críticos cubanos en muchos momentos del sistema de significados de Ismaelillo aparece invertido en "Tábanos fieros" como dantesca luminosidad de guerra: "Ya miro en polvareda/ Radiosa espolvorearse/ Aquellas escamadas/ Corazas centelleantes" (32), "Y el casco de oro en fuga/ Se pierde por los aires". "Cual sierpes de colores,/ Las flámulas ondeantes". Como ocurrirá también en la elaboración de la axiología de objetos estéticos en Versos sencillos (1891), un signo de connotación ética y luminosa puede contener el ominoso germen de su propia corrupción y devenir, desde sí mismo, antiético y umbrío -falsos destellos que Martí siempre procurará desenmascarar en su poesía y que luego resultarán claves para entender su relación con las rutilancias de la modernidad estadounidense, así como la complejidad del motor ético de sus luchas literarias, políticas y bélicas emprendidas en Nueva York durante la década que siguió a la publicación de Ismaelillo.

Pasado el fragor de la batalla, mientras las hordas enemigas se retiran -“Corren como que vuelan/ tábanos y chacales"-, el sujeto poético comienza 
a desvelar, en el descanso "... a la orilla/ De un fresco arrollo amable" (33), la fuente de su fortaleza: "¡No temo yo ni curo/ De ejércitos pujantes,/ Ni tentaciones sordas, / Ni vírgenes voraces!" porque:

Él vuela en torno mío,

Él gira, él para, él bate;

Aquí su escudo opone;

Allí su clava blande

A diestra y a siniestra

Mandobla, quiebra, esparce;

Recibe en su escudillo

Lluvia de dardos hábiles [...]

El hijo, en otras piezas recordado o imaginado siempre articulando el sistema ético de la obra completa, penetra la gramática de este poema de pesadillas como entidad celestial para proteger al padre y poner fin a su batalla contra tábanos y chacales. No puede ser el hijo real de brazos fragantes ni el hijo imaginado como monarca o príncipe, porque el lugar de este yo poético es la geografía ajena de "[t]ábanos y gigantes", habitada por el padre pero lejana a Ismaelillo, quien lo visita, cual ángel guardián, al ser invocado como fuente de protección y motivo de resistencia. Por ello él emerge como entidad "volante": "Él como abeja zumba,/ Él rompe y mueve el aire,/ Detiénese, ondea, deja/ Rumor de alas de ave:/ Ya mis cabellos roza;/ Ya sobre mi hombro párase; [...]" (34). Su ligera aparición opera, no obstante, como conjuro de efecto devastador en el entorno - “iYa la enemiga tropa/ Huye rota y cobarde!"”- debido al carácter omnímodamente ético de la inocencia infantil y de la alianza paterna en la concepción martiana de estos elementos poéticos: “¡Hijos, escudos fuertes, / De los cansados padres!”2 Así, el poema no puede sino concluir con una invitación al espíritu filial para volver al refugio de la patria íntima, solar y onírica, situada al final del riachuelo sencillo de aguas purificadoras:

¡Venga mi caballero,

Caballero del aire!

2 Julio Ramos dice que el saber del niño "demarca los contornos de un interior, enfáticamente defensivo, que el discurso poético va llenando con los signos de un mundo devaluado... opuesto a los valores dominantes de los discursos "fuertes" de la racionalidad moderna" $(1996,158)$. 


\section{¡Véngase mi desnudo \\ Guerrero de alas de ave! \\ Y echemos por la vía \\ Que va a ese arrollo amable, \\ $\mathrm{Y}$ con sus aguas frescas \\ Bañe mi hilo de sangre!}

El pesadillesco territorio poético de "Tábanos fieros", paréntesis epistémico de Ismaelillo al proyectar una geografía poética de guerra diversa de los espacios íntimos y amorosos que escenifican la pedagogía patriótica transmitida de padre a hijo, puede ser considerado, junto con el "Prólogo" a Poema del Niágara del venezolano Juan Antonio Pérez Bonalde, una alegoría que comienza a sintomatizar la experiencia moderna de Martí en Estados Unidos. Publicados en 1882, ambos textos prefiguran esa bifurcación axiológica característica de la poética martiana que coloca de un lado los "falsos" valores del entorno y del otro, la resistencia ética del poeta -división profundizada luego en Versos sencillos, espacio donde el yo lírico escuda su resistencia tras un sistema de objetos estéticos con los que enfrenta el glosario de la rutilancia engañadora de la modernidad. Y si bien el léxico de "Tábanos fieros" no hace referencia explícita a las características de la nueva época ni a la relación de esta con el artista, creemos, a partir de su singular posición con respecto a la hermenéutica desprendida de Ismaelillo y de cierta coincidencia de imágenes arteriales en ambos textos, que una lectura comparativa acaso puede iluminar las intrincadas topologías de paternidad, patria y guerra que examinamos en esta reflexión.

Entre los objetos estéticos que intersectan los imaginarios poéticos de "Tábanos fieros" y del "Prólogo" a la obra de Pérez Bonalde, esenciales son el oro y el brillo. Como argumentamos arriba para complementar la lectura de Vitier sobre el valor del signo solar en la lírica martiana, un mismo objeto de alta tasación estética, como la luz, puede denotar, desde otro ángulo, su propia degradación. De esta manera es como funciona la simbología de los falsos valores en los textos citados. Dicen el "Prólogo" y "Tábanos fieros", respectivamente:

¡Ruines tiempos, en que no priva más arte que el de llenar bien los graneros de la casa, y sentarse en silla de oro, y vivir todo dorado; sin ver que la naturaleza humana no ha de cambiar de cómo es, y con sacar el oro afuera, no se hace sino quedarse sin oro alguno adentro! (223)

Lidiemos, no a la lumbre

Del sol suave, Sino al funesto brillo 
De los cortantes

Hierros $[\ldots](30)$

En ambos casos, una misma imagen de alto contenido estético -es decir, un tropo de connotación lírica "positiva" vinculado, en este caso, al signo solar- se bifurca para generar su opuesto ético. En la cita del "Prólogo", las dos primeras alusiones al oro como metáfora de ostentación superficial difieren de su última mención como imagen de integridad o pureza interior. En los versos de "Tábanos fieros", lumbre y brillo refieren a una luz de connotaciones diferentes: el fragor de la batalla en esa hostil geografía, no puede darse "a la lumbre del sol suave", "sino [solo] al funesto brillo de los cortantes hierros". Como afirma Vitier, si en la poética martiana la luz del sol sintetiza su idea de lo ético como imagen de pureza, transparencia, sinceridad, sencillez, verdad, la luz emanada por el brillo de hierros cortantes, de armas mortales, es una "lumbre" falsa, oscura, peligrosa, que alude a la rutilancias engañosas de un entorno que al yo lírico le resulta ajeno y que es alegorizado como lugar de tentaciones. Asimismo, es posible sugerir que la bifurcación de este signo presagia, en el contexto de la batalla ética contra los tábanos fieros, la guerra "sincera" que en Versos sencillos se leerá sintomatizada en bifurcaciones trópicas similares y en momentos como el ritual encuentro del yo lírico con los héroes de mármol: "De piedra les beso: abren/ Los ojos de piedra: tiemblan/ Las barbas de piedra: empuñan/ La espada de piedra: lloran:/ ¡Vibra la espada en la vaina!/ Mudo les beso la mano" (123)

El recurso retórico de bifurcación de la metáfora, al que llamo tropo antitético, es fundamental para entender la manera en que Martí construye, en obras contemporáneas y posteriores, una poética como tensión ética entre espacios o entidades opuestas. Para Julio Ramos, esta operación parte del "concepto aurático de cultura" (259) presente en la escritura martiana en crónicas tan tempranas como "Coney Island", donde el poeta señala, por ejemplo, respecto de estadounidenses y latinoamericanos: "Aquellas gentes comen cantidad; nosotros clase" (127). La fuerza del tropo antitético como comentario valórico y como crítica aterrada a un entorno hostil proviene,

\footnotetext{
En "Lecturas filiales de José Martí”, Rafael Rojas examina las genealogías poéticas creadas por Martí en relación no solo con sus descendientes, sino también con sus progenitores espirituales. Como "padre histórico de todas las repúblicas del Nuevo Mundo", Bolívar ocupa un lugar central que, además, corrige "la orfandad del sujeto colonial y [es] propiciadora del republicanismo postcolonial" (31).
} 
según creo, del anticipo de la angustia vertiginosa provocada por lo que en 1919 Sigmund Freud definió como "lo ominoso", y de la angustia que el propio Martí, según consigna en el prólogo a Versos sencillos (1891), terminaría sintiendo en el invierno de 1890 tras asistir a la Primera Conferencia Panamericana convocada por el gobierno estadounidense el año anterior para establecer una relación hegemónica con el resto del continente. Lo ominoso, dice Freud, "pertenece al orden de lo terrorífico, de lo que excita angustia y horror" (219) y se manifiesta como una pérdida de orientación porque "lo que [ha] esta[do] destinado a permanecer en secreto, en lo oculto, ha salido a la luz" (225). A lo largo de la poética martiana, la tasación de "lo bello" tiene directa relación con su contenido ético, a nivel filosófico y artístico, de modo que si una imagen carece de él o si surge apenas como destreza del ingenio, es entonces un valor falso, una lumbre funesta, un oro superficial, una flor de artificio. Esta tensión metafórica llega a alcanzar ribetes terroríficos en un poema como "Tábanos fieros", porque ya a inicios de la década de 1880 Martí percibe con angustia la tendencia de sus contemporáneos nuestroamericanos a dejarse llevar por lumbres falsas, como las manifestaciones de modernidad que registra en sus escenas norteamericanas y que busca apuntar como potenciales portadoras de antivalores.

El particular trabajo con la metáfora, así como su amplio rango valórico, es un aspecto notado también por Gabriela Mistral en "La lengua de Marti'" (1931), cuando afirma que "el corazón es el proveedor de la metáfora en Martí" (110) y que: "En la montaña de un millón de metáforas yo creo que se puede descomponer el alma entera de Martí en su extraña contradicción de lenguas de fuego y de vellones recién cortados de ternura, en su remesón de entraña y en su soplo o silbos rápidos, de cariño y, a veces, de gozo" (111). Esta característica de la poética martiana tiene estrecha relación con la "sinceridad" del yo lírico respecto de los tábanos fieros o del poeta frente a los ruines tiempos, otra intersección de los imaginarios poéticos de ambos textos. La sinceridad, sencillez o función ética del artista -que será eje articulador de Versos sencillos según decreta su primer verso: "Yo soy un hombre sincero" (63) - es representada en el "Prólogo" mediante la simbología objetiva de los "pobres poetas" (224), quienes, pese a ser su "natural oficio sacarse del pecho las águilas que en él les nacen sin cesar" -imagen que se repite en "Musa traviesa”: "De águilas diminutas/ Puéblase el aire:/ ¡Son las ideas, que ascienden,/ Rotas sus cárceles!" (15)-, por causa de la época "ha[n] mudado de labor, y anda[n] ahogando águilas" pues los hombres "apenas tienen... tiempo para beber el oro de los vasos" y por ello no han de seguir su vuelo. 
Otros cultivarán "huecas rimas" (238), pero no el yo lírico imaginado por Martí en este texto: "poeta sincero y honrado, que te alimentas de ti mismo" (237), "poeta que se palpa el corazón, que lucha con la mano vuelta al cielo", "braceador que pone el pie seguro... en ese haz de despojos de templos... y cadáveres dorados", cultivador de "perlas buenas y sencillas, sacadas de lo hondo del alma" (229). En contraste, la resistencia ética del yo lírico de "Tábanos fieros" se presenta como batalla en la simbología subjetiva sobre los tormentos del artista en una espacialidad hostil: “. . ya vienen, ya vienen/ Mis talismanes!" (31), con los cuales "La desdentada envidia/ Irá, secas las fauces" y "Vestido irá de oro/ El diablo formidable”: "Esos gigantes:/ ¡Ligeros como nubes/ Volando iránse!".

Aunque las simbologías del "Prólogo" y de "Tábanos fieros" apuntan ambas a una dialéctica entre el artista y su entorno, surgen de lugares epistémicos diferentes: si el poeta es objeto de reflexión en el primer texto, es en cambio sujeto de tormento en el segundo. Como buen conocedor del oficio, Martí diagnostica, en el prólogo, la causa de la dolorosa situación de los poetas coetáneos; por su parte, el yo lírico performatiza, en el poema, el efecto de la hostilidad externa en una subjetividad que lucha contra "hermosas fieras interiores" (225) que buscan arrancarle la virtud y que reiteran su presencia en la hermenéutica de Ismaelillo -perturbando el metro por medio de encabalgamiento-, para ser, no obstante, neutralizadas con la omnipotencia ética del hijo:

Él me ciñe las sienes
Con su redondo
Brazo, cuando a las fieras
Penas me postro:-
Cuando el cabello hirsuto
Yérguese y hosco,
Cual de interna tormenta
Símbolo torvo ("Sobre mi hombro" 28).

Este vínculo posible entre ambas obras no debería extrañar si consideramos que la poética oscilante del prólogo sugiere, entre otras fuentes de reflexión, una premisa autorreferencial: al hablar del artista en la nueva época, Martí fluctúa desde una abstracta idea de los "bardos modernos" (228) o "pobres poetas": "hombres magnos" (224); pasando a ratos por Pérez Bonalde: "catecúmeno enérgico" (232); y deteniéndose muchas veces en sí mismo como parte del genérico "hombre moderno" (237): "este cambio de quicio 
a que asistimos" (229), o en sí mismo como poeta: "[s]iente uno, luego de escribir, orgullo de escultor y de pintor" (234). Podemos entonces retomar la proposición inicial acerca de la poesía como espacio de refugio para el yo lírico y complementar, con este examen de la modernidad implícita en estas piezas, nuestra propuesta inicial de la migración, en el contexto del exilio, de la voz poética desde lo épico a lo lírico: "lastimados los pies y los ojos de ver y andar por ruinas que aún humean, reentra en sí el poeta lírico, que siempre fue... poeta personal $[\mathrm{y}]$ que hubiera sido en épocas cortesanas, conventuales o sangrientas, poeta de epopeya" (229). El "Prólogo" insinúa, asimismo, la migración del lugar epistémico de la patria versificada desde la colectividad colonizada a la subjetividad desterrada, porque de esos "ruines tiempos", en que "aparece en la naturaleza contradictorio todo lo que es lógico" (224) y en que "[n]adie tiene... su fe segura" (225), es hija "esa nueva poesía atormentada y dolorosa" (224), "íntima, confidencial y personal", "ingenua y útil". Así, tanto la poética íntima e infantil rectora de Ismaelillo como el paréntesis amargo y angustiado de "Tábanos fieros", pueden leerse como reacción sintomática al espanto de poetas "reveladores y veedores", que no han perdido la fe "en la utilidad de la virtud" (41), frente a esa época de "ruinas que aún humean" (229) y de "confusas... instituciones nacientes". Incluso la patria íntima que el yo lírico construye junto al hijo ausente -así como el implícito deber bélico del padre para concretarla: "tienen los poetas hoy... la nostalgia de la hazaña [pues] [1]a guerra, antes fuente de gloria, cae en desuso" (228)- encuentra su premisa en la reflexión martiana sobre los ruines tiempos modernos: "¿qué es nuestro cerebro, sementera de proezas, sino anuncio del país cierto en que han de rematarse?” (236).

Ismaelillo puede ser, entonces, poesía como "necesaria consecuencia de los tiempos" (224), porque no "cabe más lírica que la que saca cada uno de sí propio" (225) y porque no cabe más que llenar las copas "de perlas buenas y sencillas, sacadas de lo hondo del alma" (229). Es en este sentido que la primera poesía del exilio de Martí, cargada de versos éticos, de refugio y resistencia a un entorno que comienza a revelarse dolorosamente confuso y ominosamente dorado, puede localizarse en los albores de las sensibilidades que perciben la crisis de la modernidad. Como señala Ramos, hablando de la autonomización del saber literario, a fines del siglo XIX emerge "un sujeto literario... que erige su voz por el reverso -y como crítica- de la racionalización, su voz cargada de valor "espiritual" precisamente en un mundo ya desencantado y mercantilizado" (81). Es una estética surgida en reverso de una modernidad que la palabra martiana comienza a articular a 
partir de un léxico de la amenaza, la cual es provocada por la angustia moderna de la desfamiliarización de lo conocido y de la falsedad de muchas formas y lumbres. Y en su afán de sujeto colonial moderno de buscar refugios (po) éticos a los signos de un entorno inquietante - "Una tormenta es más bella que una locomotora" (234)-, la mirada del yo lírico apunta, inevitablemente, a la patria oprimida que en el exilio se carga en el alma, imaginándola como país cierto, como una Cuba libre para Ismaelillo construida sobre sus geografías poéticas del exilio.

Los tábanos fieros o los vicios de la nueva época, de momento articulados subjetivamente como hermosas fieras interiores, irán poco a poco adquiriendo identidad y localización específicas en la retórica colectiva martiana, cristalizando, hacia el final de la década de 1880, en el monstruo de conocidas entrañas y que será menester combatir. Es el momento en que la modernidad estadounidense registrada en su crónica choca de frente con la patria imaginada en la intimidad poética, tras constatar, en sus labores como reportero durante las Conferencias Panamericanas, las intenciones de Estados Unidos respecto de Cuba. Martí, no obstante, se aferrará hasta Versos sencillos a sus geografías poéticas de la sinceridad para transitar a la configuración de un espacio bélico también sincero, porque, aun "empujado a esa cueva de fieras hediondas que ha solido ser en la historia la guerra", según apunta Mistral, "este extraño combatiente con cara que echa de sus planos resplandores, va a pelear sin malas artes" (114). El final de la década de 1880 es también el momento en que los saberes intuitivos construidos sobre la angustia moderna de un entorno que ya en Ismaelillo emerge de una desfamiliarización, se convierten en un programa continental que "brings into light both coloniality and the epistemic potential of non-European epistemes" (Maldonado-Torres 30). Según revela su primera poesía del exilio, desde temprano la patria masculina imaginada por José Martí apunta a su corporización como desafío viril y sacrificio imperioso ante la incertidumbre del porvenir -tareas que el "pecho bravo" del cuerpo real del poeta asume en su última obra bajo la convicción de la "guerra necesaria". La manera como hacer frente a este deber era clara para Martí ya en sus obras de 1882:

...caliéntate a la llama saludable del frío de estos tiempos dolorosos en que... están todos los hombres de pie sobre la tierra, apretados los labios, desnudo el pecho bravo y vuelto el puño al cielo, demandando a la vida su secreto ("Prólogo" 238).

¿Qué el mundo frágil?

Pues ¿no saben los hombres 
Qué encargo traen?

¡Rasgarse el bravo pecho,

Vaciar su sangre... ("Musa traviesa" 13)

\section{BIBLIOGRAFÍA}

Freud, Sigmund. "Lo ominoso". 1919. Obras completas, vol. XVII. Buenos Aires: Amorrortu Editores, 1992. 215-251.

Maldonado-Torres, Nelson. "The Topology of Being and the Geopolitics of Knowledge. Modernity, Empire, Coloniality". City, Vol. 8, No. 1 (april 2004): 29-56.

Martí, José. “ ¡10 de octubre!” 1868. Obras completas. T. 17. La Habana: Editorial de Ciencias Sociales, 1975. 20. 121-128.

"Coney Island". 1881. OC. T. 9. La Habana: Editorial de Ciencias Sociales, 1975.

"El Poema del Niágara". 1882. OC. T. 7. La Habana: Editorial de Ciencias Sociales, 1975. 221-238.

Ismaelillo. 1882. Matanzas: Ediciones Matanzas y Ediciones Vigía, 1992.

Versos sencillos. 1892. OC. T. 16. La Habana: Editorial de Ciencias Sociales, 1975. 55-126.

Mistral, Gabriela. "La lengua de Marti". 1931. Anales de la Universidad de Chile. No. 89. Santiago (año 111, 1953): 97-116.

Molloy, Sylvia. "His America, Our America: José Martí Reads Whitman". Doris Sommer (ed.). The Place of History, Regionalism Revisited in Latin America. Durham: Duke University Press, 1999. 262-271.

Paz, Octavio. Los hijos del limo. Del romanticismo a la vanguardia. Barcelona: Seix Barral, 1974.

Ramos, Julio. Paradojas de la letra. Caracas: Ediciones eXcultura, 1996.

Desencuentros de la modernidad en América Latina. Literatura y política en el siglo XIX. 1989. Santiago de Chile: Editorial Cuarto Propio/ Ediciones Callejón, 2003.

Rojas, Rafael. “Lecturas filiales de José Martí”. Revista Hispánica Moderna Año 57, No. 1-2 (junio-diciembre 2004): 19-35.

Schulman, Iván. "Los supuestos precursors" del modernismo hispanoamericano". Nueva Revista de Filología Hispánica. Año 12, No. 1. El Colegio de México (enero-marzo 1958): 61-64.

Vitier, Cintio. "Introducción". José Martí. Obra literaria. Caracas: Biblioteca Ayacucho, 1978.

"Trasluces de Ismaelillo". Cintio Vitier y Fina García Marruz. Temas martianos. La Habana: Departamento Colección Cubana, Biblioteca Nacional José Martí, 1969. 141-151. 